Z Epileptol 2017 · 30:305

https://doi.org/10.1007/s10309-017-0151-0

Online publiziert: 29. September 2017

๑) Springer Medizin Verlag GmbH 2017

CrossMark
Gunter Gross-Selbeck

Düsseldorf, Deutschland

\title{
Laudatio zum 90. Geburtstag von Herrn Professor Dr. Hermann Doose
}

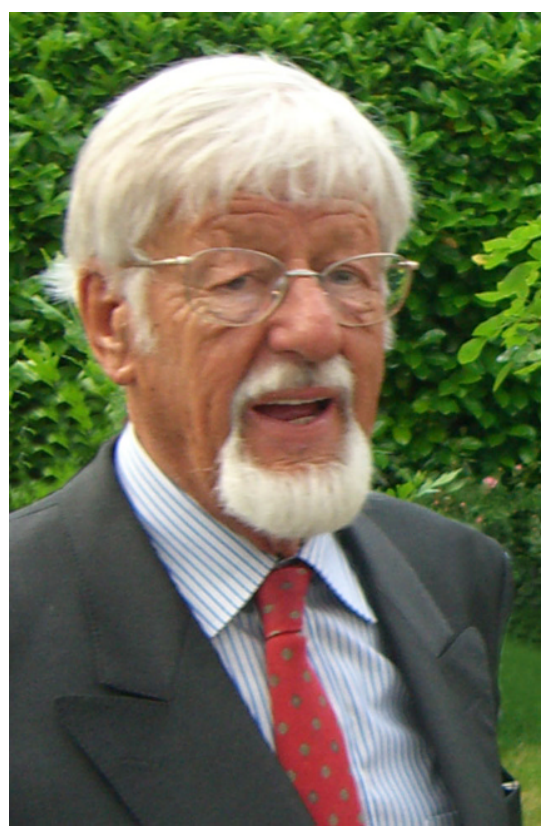

Prof. Dr. med. Hermann Doose

Am 9. September d. J. vollendete Prof. Hermann Doose sein 90. Lebensjahr. Eine kleine Gruppe ehemaliger Mitarbeiter aus der Universitätskinderklinik Kiel und dem Norddeutschen EpilepsieZentrum Raisdorf hat ihn und seine Frau an seinem Ehrentag in seinem Haus in Kronshagen bei Kiel besucht und Glückwünsche überbracht.

Hermann Doose gehört zu den herausragenden pädiatrischen Epileptologen in Deutschland und genießt hohes internationales Ansehen. Von 1975 bis 1992 war er Direktor der Klinik für Neuropädiatrie der Universität Kiel und ärztlicher Leiter des auf seine Initiative 1972 eröffneten Norddeutschen Epilepsie-Zentrums für Kinder und Jugendliche in Raisdorf bei Kiel.
Wissenschaftlich beschäftigte er sich vorrangig mit den genetischen Ursachen der Epilepsien anhand von umfangreichen Familienuntersuchungen, insbesondere mit den erblichen EEGVarianten. Aus seiner Feder stammt eine Vielzahl von Publikationen v. a. zur Syndromatologie kindlicher Epilepsien. 1970 beschrieb er erstmals die frühkindliche primär generalisierte myoklonischastatische Epilepsie, später v. a. im internationalen Schrifttum als „DooseSyndrom" bekannt.

Doose war 1976 Vorsitzender der Gesellschaft für Neuropädiatrie und von 1977 bis 1979 Vorsitzender der Deutschen Sektion der Internationalen Liga gegen Epilepsie (seit 2004 Deutsche Gesellschaft für Epileptologie). $1963 \mathrm{er}-$ hielt er den Preis der Stiftung Michael, 1985 den Hans-Berger-Preis der Deutschen EEG-Gesellschaft (Deutsche Gesellschaft für Klinische Neurophysiologie) und 2004 die Otfrid-Foerster-Medaille der Deutschen Gesellschaft für Epileptologie. 1975 wurde er von der Internationalen Liga gegen Epilepsie zum „Ambassador for Epilepsy“ ernannt. Doose ist Ehrenmitglied der Deutschen Gesellschaft für Epileptologie, der Gesellschaft für Neuropädiatrie und der Italienischen Sektion der Internationalen Liga gegen Epilepsie.

In jedem Bücherschrank eines Kinderarztes und Neurologen zu finden waren Dooses Zerebrale Anfälle im Kindesalter (später Epilepsien im Kindesund Jugendalter), ein Buch, das sich an Studenten und junge Ärzte wandte, um ihnen ein fundiertes Basiswissen über zerebrale Anfälle und Epilepsien im Kindesalter zu vermitteln. Das Buch kam erstmals 1970 im Desitin-Verlag auf den Markt, ist in 11 weiteren Auflagen erschienen und war seinerzeit praktisch konkurrenzlos. Die letzte Auflage aus der Hand von Hermann Doose stammt aus dem Jahr 1998. Seitdem erlebt es im Springer-Verlag - herausgegeben von Neubauer und Hahn - unter dem Titel Dooses Epilepsien im Kindes- und Jugendalter weitere Auflagen.

Bei unserem Besuch in seinem Hause konnten wir mit Herrn Doose zahlreiche Erinnerungen aus früherer Zeit wiederaufleben lassen. Wir als ehemalige Mitarbeiter haben das ausgesprochen gute Arbeitsklima, das seinerzeit nicht nur in seiner Klinik, sondern in der gesamten Kinderklinik herrschte, sehr zu schätzen gewusst, wozu nicht zuletzt die legendären Einladungen in seinem Hause („bis die Nachtigall auf dem Dachfirst singt") beigetragen haben.

\section{Korrespondenzadresse}

Prof. Dr. G. Gross-Selbeck

Neanderstr. 6, 40233 Düsseldorf, Deutschland gunter.selbeck@gmail.com 